holm. The commissioners having presented a report of their work to his Majesty, he has graciously signified his approval of the following final propositions of theirs.

Having taken into consideration the questions which from different points of view equally engage the attention of analysts, and the solution of which would be of the greatest interest for the progress of science, the commission respectfully proposes to his Majesty to award the prize to the best memoir on one of the following subjects :-

I. A system being given of a number whatever of particles attracting one another mutually according to Newton's law, it is proposed, on the assumption that there never takes place an impact of two particles, to expand the coordinates of each particle in a series proceeding according to some known functions of time and converging uniformly for any space of time.

It seems that this problem, the solution of which will considerably enlarge our knowledge with regard to the system of the universe, might be solved by means of the analytical resources at our present disposition; this may at least be fairly supposed, because shortly before his death Lejeune-Dirichlet communicated to a friend of his, a mathematician, that he had discovered a method of integrating the differential equations of mechanics, and that he had succeeded, by applying this method, to demonstrate the stability of our planetary system in an absolutely strict manner. Unfortunately we know nothing about this method except that the starting-point for its discovery seems to have been the theory of infinitely small oscillations. ${ }^{1}$ It may, however, be st:pposed almost with certainty that this method was not based on long and complicated calculations, but on the development of a simple fundamental idea, which one may reasonably hope to find again by means of earnest and persevering study.

However, in case no one should succeed in solving the proposed problem within the period of the competition, the prize might be awarded to a work in which some other problem of mechanics is treated in the indicated manner and completely solved.

(2) Mr. Fuchs has demonstrated in several of his memoirs ${ }^{2}$ that there exist uniform functions of two variables which, by their mode of generation, are connected with the ultra-elliptical functions, but are more general than these, and which would probably acquire great importance for analysis, if their theory were further developed.

It is proposed to obtain in an explicit form those functions whose existence has been proved by Mr. Fuchs, in a sufficiently general case, so as to allow of an insight into and study of their most essential properties.

(3) A study of the functions defined by a sufficiently general differential equation of the first order, the first member of which is a rational integral function with respect to the variable, the function, and its first differential coefficient.

Mr. Briot and Mr. Bouquet have opened the way for such a study by their memoir on this subject (Fournal de l'Ecole polytechnique, cahier 36, pp. 133-198). But mathematicians acquainted with the results attained by these authors know also that their work has not by any means exhausted the difficult and important subject which they have first treated. It seems probable that, if fresh inquiries were to be undertaken in the same direction, they might lead to theorems of high interest for analysis.

(4) It is well known how much light has been thrown on the general theory of algebraic equations by the study of the special functions to which the division of the circle into equal parts and the division of the argument of the elliptic functions by a whole number lead up. That remarkable transcendant which is obtained by expressing the module of an elliptic function by the quotient of the periods leads likewise to the modulary equations, that have been the origin of entirely new notions and highly important results, as the solution of equations of the fifth degree.

I See p. 35 of the Panegyric on Lejeune-Dirichlet by Kummer, "Abhandlungen der K. Akademie der Wissenschaften zu Berlin," I860.

${ }_{2}$ These memoirs are to be found in-(I) "Nachrichten von der $K$ Gesellschaft der Wissenschaften zu Göttingen," February, r88o, p. 170; (2) Borchardt's "Journal," Bd. 89 , p. $25 \mathrm{I}$ (a translation of this memoir is to be found in the "Bulletin" of Mr. Darboux, 2me. série, t. iv.); (3) "Nach richten von der K. Gesellschaft der Wissenschaften zu Göttingen," June, 1880, p. 445 (translated into French in the "Bulletin" of Mr. Darboux me série, t. iv.)! (4) Borchardt's "Journal," Bd. 9o, p. $7 x$ (also in the "Bull etin" of Mr. Darboux, me série, t. iv.); (5) "Abhandlungen der K. Gesellschaft der Wissenschaften zu Gottingen," 1881 ("Bulletin " of Mr. Darboux, t. v.) ; (6) "Sitzungsberichte der K. Akademie der Wissenschaften zu Berlin," I883, i. p. $507 ;(7)$ The memoir of M. Fuchs published in Borchardt' "Journal," Bd. 76," p. I77, has also some bearings on the memoirs quoted.
But this transcendant is but the first term, a particular case and that the simplest one of an infinite series of new functions introduced into science by Mr. Poincaré under the name of "fonctions fuchsiennes," and successfully applied by him to the integration of lineary differential equations of any order. These functions, which accordingly have a rôle of manifest importance in analysis, have not as yet been considered from an algebraical point of view as the transcendant of the theory of elliptic functions of which they are the generalisation.

It is proposed to fill up this gap and to arrive at new equations analogous to the modulary equations by studying, though it were only in a particular case, the formation and properties of the algebraic relations that connect two "fonctions fuchsiennes" when they have a group in common.

In case none of the memoirs tendered for competition on any of the subjects proposed above should be deemed worthy of the prize, this may be adjudged to a memoir sent in for competition that contains a complete solution of an important question of the theory of functions other than those proposed by the Com. mission.

The memoirs offered for competition should be furnished with an epigraph and, besides, with the author's name and place of residence in a sealed cover, and directed to the chief editor of the Acta Mathematica before June I, I888.

The memoir to which his Majesty shall be pleased to award the prize as well as that or those memoirs which may be considered by the Commission worthy of an honorary mention, will be inserted in the Acta Mathematica, nor can any of them be previously published.

The memoirs may be written in any language that the author chooses, but as the members of the Commission belong to three different nations the author ought to subjoin a French translation to his original memoir, in case it is not written in French. If such a translation is not subjoined the author must allow the Commission to have one made for their own use.

The Editors of the "ACta Mathematica"

\section{DR. PERKIN ON THE COAL-TAR COLOURS 1}

TAKING a precedent from some of those who have occupied this chair before me, I have selected for my few remarks to-day the subject in relation to Technical Chemistry, with which I have been personally connected-namely, the colouring matters produced from coal-tar products, with some of the lessons its development appears to me to teach is in connection with industrial chemistry. Sir Frederick Abel, in his address in I 883 , when speaking of the history of gunpowder, said that "It is one of the most remarkable features connected with the history of gunpowder, that until the last quarter of a century no radical changes should have been introduced into the manufacture and modes of applying this, the first known practically useful explosive agent." It appears to me that this is more or less true of all the older industries, which resulted simply from experiment and observation without any other basis to work from. They have had long histories in which little progress has been made, but of late years, owing to our advanced and rapidly increasing scientific knowledge, they are undergoing great, and in many cases radical, changes.

The coal-tar colour industry stands in a very different position to our older ones. It has a sharply-defined origin, and a very short history dating back only to 1856 , and it is not yet twentynine years since the date of the first patent. It is an industry which has been founded on scientific discovery, and has developed side by side with it, being in fact a most important handmaid to research, which in its turn has repaid it by new discoveries. At the date of its introduction very little was known of the chemistry of colouring matters; they were always found difficult bodies to investigate, and when produced in reaction were generally regarded as secondary products, and every endeavour was made to get rid of them so that the other products associated with them might be examined; but now, owing to the very extended study which has been made of these bodies, on account of this industry, and the relationships which have been found to exist between the colour of the compounds and the chemical constitution, it is possible with more or less certainty to predict the colour a compound will have before it is produced, and the means which can be used to modify it.

The President's address, Institute of Chemistry. 
It will be impossible for me to give you but a very brief sketch of the history of this industry in the time at my disposal ; anything like a complete account would fill volumes. On account of this I shall not be able to refer except casually to the coal-tar industry itself, the development of which is nearly entirely due to the one under consideration. Nor can I give a consecutive account of the coal-tar colours themselves, because the discovery of new series of colouring matters, and the progress of old ones, necessarily produce overlapping as it were, and renders such a course difficult and confusing. I therefore propose to take them according to the groups we now know them to belong to. I will therefore commence with that which contains the first colouring matter connected with this industry-mauvein and safranine group of compounds.

As I already mentioned, the coal-tar colour industry dates from 1856 , the discovery of the aniline purple or matve dye being madc during the Easter vacation of that year, and the patent for its production taken out on the 26th of the following August. From the accounts I have already given elsewhere, I have mentioned how the discovery of this colouring matter was made during the prosecution of scientific research, which had for its object the artificial production of quinine, a subject which of late has very much occupied the attention of chemists, though it has not as yet been accomplished.

When commencing this industry, which was looked upon by many with considerable doubt as to its practicability, the difficulties encountered were very numerous on account of its unique character, but few of the processes having their representatives in other industries, the products were also very valuable, so that great care had to be employed with them. The success of the product tinctorially had not been proved on the large scale, so that it was necessary to proceed tentatively and not launch out too rapidly.

Aniline, as is well known, was at this period a rare body, originally obtained from indigo by Unverdorben in 1826 , but for its production from benzene we are first indebted to the discovery of nitrobenzenein 1834 by Mitcherlich, and then to Zineri, who found that this substance when submitted to certain reducing agents produced a base which was eventually identified as aniline. It was not long before the date of this industry that a method of producing this base from nitrobenzene, with greater ease than by the process of Zinin, was discovered; and it is to Beauchaump we are indebted for this, who found that the reduction might be easily accomplished by means of iron filings and acetic acid. Had this discovery not been made, aniline could not have been produced sufficiently cheap to be used for the production of colouring matters. And it is interesting to note that this process of Beauchaump, slightly modified, is the one used to-clay for the production not only of this base, but its homologues and analogous compounds.

It was not long before the difficulties of producing nitrobenzene were to a great extent overcome. Messrs. Simpson, Maule \& Nicholson also began to experiment on the production of nitrobenzene, and after a time were able to produce it at a sufficiently low cost to be able to supply us with part of our requirements. I mention this in passing because it was the starting point of the history of the connection of this firm with artificial production of colouring matter, which they carried on so successfully afterwards.

After the malve was discovered it was necessary to teach dyers how to use it. Being an organic base, it is opposite in properties to the vegetable colouring matter, and therefore the ordinary methods of application were not generally useful, and much time had to be spent in dyehouses and printworks in the early days of this product in reference to this subject, and at that time the question of fastness to light soap and bleaching liquor was much insisted on. Fortunately for the future of the coaltar colour industry, although the mauve would not resist bleaching liquor well, it proved to be a very fast colour-the fastest purple yet produced, I believe-and thus its introduction became rapid. After this the love of brilliancy of colour which it had induced caused less attention to be given to the subject of fastness. I quite think that had this, the first coal-tar colouring matter, yielded colours as fugitive as some which have since been used, this industry would probably have been, to say the least, much delayed in its progress; so that it will be seen the mauve had to bear all the burdens of the difficulties incident on the inauguration of this industry, the future products being free from these impediments. The importance of this colouring matter after its success was established was quickly recognised in France, and its manufacture commenced there. This soon resulted in its importation into this country irrespective of patent rights. As, however, the foreign manufacturer employed responsible agents in this country, the law was without difficulty put into operation successfully-unfortunately, however, only to teach Continental manufacturers the lesson not to employ responsible agents in this country any longer, but, by means of correspondence or travellers, to deal directly with the consumers, and this modus operandi (practically, though perhaps not theoretically) enabled them to ignore the existence of patents, and import their products freely into this country. On this point I shall have to speak again further on. The mauve was first employed in silk dyeing in London, Mr.iThomas Keith \& Sons, of Bethnal Green, being the first to use it. The second application was calico printing, Messrs. James Black \& Co., of Glasgow, being the first to employ it largely for this purpose. It afterwards was extended to other trades.

With 'reference to the chemical history of this dye, although it had been submitted to analysis very soon after its discovery, its formula, or rather the formula of its principal constituent "maurein," was not established until some time after it had become a commercial product, and was prepared in a crystalline condition. It was then shown to have the composition $\mathrm{C}_{27} \mathrm{H}_{24} \mathrm{~N}_{4}$ (Proc. $R$. S. xiii. 170).

It was found to be a very powerful base, decomposing ammonia salts with evolution of ammonia, and combining with carbonic acid to form a carbonate. Its ordinary salts are produced by its combination with one molecule of a mono-basic acid, its hyclrochloride being $\mathrm{C}_{27} \mathrm{H}_{34} \mathrm{~N}_{4} \mathrm{HCl}$.

In concentrated sulphuric acid it dissolves with a dirty green colour, changing to blue on slight dilution, and back to purple when thoroughly diluted; this is a distinctive reaction of this class of substance. Further researches have shown $(\mathscr{F}$. Chem. Soc. xxxv. 717-732) that in the ordinary colouring matter there are two other compounds, one which is remarkable for its solubility, and from analysis appears to have the composition $\mathrm{C}_{24} \mathrm{H}_{20} \mathrm{~N}_{4}$; and the third, which has not been fully examined, possesses a redder shade of purple than the other.

The first product, or mauvein, is cvidently a derivative of paratoluidine and aniline. The third of orthotoluidine and aniline, and the second of pure aniline. This has been called pseudo-mauvein. It might perhaps be better called phenolmauvein.

When boiled with aniline mauvein yields an indigo-blue product, difficultly soluble in alcohol. This change takes place without formation of ammonia, and shows how different mauvein is in its character to rosaniline.

Runge found that aniline, when treated with dilute chloride of lime, yielded a blue- or violet- coloured solution, which soon underwent change. Some experiments on this, made in 1868 (7. Chem. Soc. xxii. 25-27), showed that the product which I termed "Runge's blue," was a peculiar compound, the salt of an organic base, which itself dissolved in alcohol with a reddish brown colour, the salts being blue. It is quite different from mauvein, and of no practical value; but what is interesting is that when exposed to heat, as by boiling a solution of one of its salts, it decomposes with formation of mauvein.

A beautiful colouring matter was obtained from mauvein by treating it with ethylic iodide. It gives shades of colour of a very red purple tint, and it was therefore called dahlia. It was mostly used in calico and delaine and other kinds of printing, but being costly, the production was never very large. This substance is a mono-ethylic derivative of mauvein, and all attempts to further ethylate this compound have proved fruitless. In properties it appears to be more like an ammonium compound than a replacement product.

Safranines. - In the preparation of mauvein, a colouring matter was obtained from the liquors, from which it was precipitated, producing beautiful crimson-red shades of colour on silk. The amount produced in this way was so small, however, that we are even not able to introduce it as a dye. But it was found that it could be produced by the oxidation of the mauve dye itself, and was then manufactured under the name of "aniline pink," but afterwards "safranine." This substance is evidently closely related to mauvein, as it gives the characteristic reaction with sulphuric acid I have already referred to.

The preparation of this from the mauve dye was, however, too costly to allow of its being brought into general use. How ever, new processes have been since discovered, by which this or other colouring matters of its class can be produced cheaply. 
The first of these processes consisted in passing nitrous acid into commercial aniline, and then heating the mixture with arsenic acid, and then extracting the colouring matter produced. Hofmann examined this, and showed that it had the formula $\mathrm{C}_{21} \mathrm{H}_{20} \mathrm{~N}_{4}$ (Ber. vi. 526,1872 ).

The examination of the product which was obtained by oxidising the mauve dye, I found to have the composition, $\mathrm{C}_{20} \mathrm{H}_{18} \mathrm{~N}_{4}$ (F. Chem. Soc, xxxv. 73I), results which correspond with analyses published by Dale and Schorlemmer (F. Chem. Soc, xxxv. 682), obtained from the examination of a similar product. This substance, I found, was associated with that examined by Hofmann in a product prepared by Messrs. Guinon \& Co., of Lyons.

Methods of a more synthetical nature have since then been discovered. $O$. Witt found that safranine could be obtained from orthoazotoluene and hydrochloride of toluene at $150-200^{\circ}$ (Ber. x., 874, r877). He then found that by oxidising a mixture of one part of paraphenylenediamine, and two parts of aniline, on the application of heat a safranine could be obtained which has the formula, $\mathrm{C}_{18} \mathrm{H}_{16} \mathrm{~N}_{4}$, and which is called phenosafranine.

The formation of this colouring matter by this and other processes has been studied by Nietzki (Ber. xvi. 464). He finds that the aniline in the reaction, in which paraphenylenediamine takes part, may be substituted by other primary monamines, or a mixture of these with dimethylaniline, and thus a large number of these dyes can be obtained.

Phenosafranine is now produced very largely, and in a pure crystallised condition, and is a very useful dyeing agent.

If we assume that all the safranines are strictly homologous compounds, the formula that Nietzki gives for phenosafranine would make the formula of that examined by Hofmann, and that examined by myself and Dale and Schorlemmer, to be incorrect, and that they should contain two hydrogens more than are assigned to them. This I cannot think is possible from all the analytical results we obtained.

The constitution of mauvein has not yet been established, and I have still experiments on this subject in hand. This may also be said of safranine, I think, although Nietzki has proposed a formula for it, in which nitrogen occupies a similar position to the metharacarbon in the rosaniline series.

Triphenylmethane Derivatives.-We must now go back again to the early days of this industry to consider the next class of compounds-viz., triphenylmethane derivatives.

The industrial success of the mauve dye caused aniline to become a very favourite body to experiment with, and the result was that in 1859 , the discovery of that important colouring matter first known as fuchsine or magenta took place. Hofmann had observed in his experiments on the action of carbon tetrachloride on aniline in 1858 , the formation of a red colouring matter, which consisted of this substance as a secondary product of the reaction, but it was $M$. Verquin who first discovered a process for the transformation of aniline into a red colouring matter of tinctorial value. This discovery of the compound marks a most important fresh departure in the history of coal-tar colours. As I mentioned, the mauve had paved the way for future colouring matters, and this new substance, which could be applied to fabrics by the same methods as the mauve, was most eagerly sought after owing to the brilliancy of its colour; and probably its manufacture was one of the most successful financially of all the aniline colours.

M. Verquin's process, which consisted in treating tin tetra. chloride with commercial aniline, was soon superseded by better processes. The number of patents taken out for the production of this dye was very large, and all imaginable products were claimed as capable of producing it from aniline. The two most important, however, were those in which mercury nitrate and arsenic acid were used. The first of these processes, with which I had some experience, required much care to regulate the reaction and prevent deflagration. The next process with arsenic acid, known as medlocks, was by far the best, and was used very extensively until the last few years, the use of nitrobenzene as the oxidising agent being now mostly used in the place of arsenic aicd.

The manufacture of magenta, which at this period was often called roseine, was carried on chiefly in this country by Messrs. Sampson, Maule, \& Nicholson, by the arsenic acid process. Mr. E. C. Nicholson and Dr. A. P. Price, of this firm, worked out the process with great success, and were the first to produce this colouring matter in a pure state. The beautiful display of the crystallised acetate, shown at the Exhibition of 1862 , illustrated this fully.
It was with products supplied by Mr. Nicholson that Dr. Hofmann made his first researches on this colouring matter. He changed its name from roseine to rosaniline, and found that the base, when in combination with acids, had the formula $\mathrm{C}_{20} \mathrm{H}_{19} \mathrm{~N}_{3}$.

The important observation of Nicholson, and the critical experiments of Hofmann, ion the necessity of using, not pure aniline, but a mixture of aniline and toluidine for the production of this substance, was made about this period. 1

The next important step in this industry was the use of rosaniline itself as a source of new colouring matters. For this we are indebted to the experiments of two French chemists-viz., MM. Gerard and Delaire, who discovered that rosaniline salts, when heated with aniline, gave violet and blue colouring matters, which they called Violet Imperial and Bleu de Lyon. It is, however, to $\mathrm{Mr}$. Nicholson that the credit of producing these bodies, in a practically pure state, belongs. This especially refers to the blue, the product known as opal blue, used by Dr. Hof mann in his investigations on the subject, being of great purity. Dr. Hofmann showed that these products were phenylated rosanilines, as is now well known, ammonia being given off in the reaction. And I may mention in passing that the manufacture of these blues is now carried on to such a large extent that the ammonia produced in this reaction is collected for the production of its sulphate or other salt.

One of the difficulties in the way of the new blue was its in solubility in water. Mr. Nicholson, however (in I862), probably thinking of the method used to render indigo soluble, experimented upon the action of sulphuric acid in this compound, and he found that it was possible to obtain sulphonic acids from it. One of these, the sodium salt of which is known as "Nicholson's" or "alkali blue," is the monosulphonic acid, which is itself insoluble in water, but forms soluble salts, which can be applied to the yoods, and then decomposed by acids. This compound has had much to do with the successful introduction of this colouring matter. The other product known as soluble blue is the sodium salt of trisulpho acid.

In the early part of 1864 the Hofmann violets were introduced. These, as is well known, are the ethylated rosanilines produced by acting upon rosaniline with ethyliodide. These colouring matters are more brilliant, though much more fugitive than mauvein; but by this time the desire for permanency was giving way very much to that of brilliancy; and these colouring matters were quickly taken up by dyers and calico printers.

About this time some colouring matters derived from phenol were introduced, and which, curiously, are found to belong to the class of substances now under consideration. These were brought forward by Messrs. Guinon, Marnas, and Bonnet, of Lyons. The first product was aurine, prepared from phenol by means of oxalic and sulphuric acid (Kolbe and Schavtt's process). The next was polvuine, obtained by acting upon aurine with ammonia. The third was azuline, prepared by heating aurine with aniline. This last was a blue dye, which has since been shown to consist chiefly of triphenylrosaniline.

Purple and violet derivatives were also obtained from rosaniline by a process of my own, in which brominated turpentine was employed. These were known as Britannia violets, and were much used.

Other coloured derivatives were also discovered; for example, by the action of aldehyde and sulphuric acid, a blue product was obtainel, which, when treated with sodium hyposulphite or sulphuretted hydrogen water, yielded the well-known aldehyde green.

On examining the action of acetylchloride on Britannia violet, I obtained a peculiar green, which was used principally by calico printers, and very considerable quantities of acetylchloride were prepared for this purpose. The process was not published. This green was of a blue shade, and was obtained in a crystallised condition in combination with picric acid. The crystals had a golden metallic reflection.

Soon after this it was noticed that a green compound was produced in the preparation of the Hofmann violets, though generally only. in small quantities. It was afterwards found that by making rosaniline react with an excess of methylic iodide that it could be produced practically. It was called iodine green; but the praduct now manufactured is a chloride. This colouring matter gave good candle-light greens. One of

I In my original patent it was shown that colouring matters could be obtained, not only from aniline, but also from toluidine xylidine and cumidine. 
its peculiarities is that when heated it is converted into violet methyl-rosaniline, with loss of methyl-chloride.

A new method of producing rosaniline violet was proposed by Lauth, and patented by MM. Porrier and Chappat, in June, I866. The process consisted in taking aniline, in which hydrogen had been replaced by an alcohol radical, and oxidising this instead of first preparing rosaniline, and then replacing the hydrogen in the colouring matter by the radical. The product proposed for this purpose was methyl-aniline.

Owing to the improved method of methylating aniline, which, I believe, was first proposed by Messrs. Gerard and Delaire (Bull. Chem. Soc. [2] vii. 360), this process has become a very important one, and large quantities of dimethyl-aniline are now used, the oxidation being effected by copper salts. The product, according to the reseaches of Otto Fischer, consists chiefly of pentamethylpararosaniline.

The most important advance in the production of green colouring matters of the triphenyl-methane series was the discovery of the benzaldehyde, Victoria or malachite green.

In 1877 , Otto Fischer, whilst investigating the condensation products of tertiary aromatic bases (Ber. $x_{2}, 1625$ ), obtained by the action of benzaldehyde on dimethyl-aniline in presence of chloride of zinc, a colourless base of the formula $\mathrm{C}_{23} \mathrm{H}_{26} \mathrm{~N}_{2}$, the salts of which, when exposed to the air, rapidly oxidised to a fair blue-green dyestuff, which, he thought, would prove to be of complicated constitution. A little later (Ber. xi ${ }_{1}, 950$ ) he showed that by oxidising this colourless base with some of the ordinary oxidising agents, this green could be more easily produced, and that it stood to the colourless compound in the same way as rosaniline does to leucaniline. Emil and Otto Fischer afterwards say (Ber. xii. 796) that the first experiments for the production of this green were made by the Badische Aniline und Soda Fabrik, in March, 1878. About this time Oscar Doebner (Ber. xi. 950) found that a green colouring matter was produced by heating benzaldehyde with benzyl trichloride and zinc chloride. This product has been found to be identical with that of Fischer's. This green colouring matter is now largely made from benzaldehyde, as this process is found to be the best. A similar compound is also prepared from diethyl-aniline, and is known as brilliant green. It is a beautifully crystalline body. It is rather curious that this produces shades of colour somewhat yellower than the green from dimethyl-aniline, whereas, being of a higher molecular weight, we should have expected it to be blue.

The principal difficulty which had to be contended with in the production of these colouring matlers was the need of a supply of benzaldehyde The usual method of obtaining it from bitter almonds, which was the only one in use, was quite out of the question, so that other sources had to be lo sked for. The Badisches Aniline und Soda Fabrik, however, successfully overcame this difficulty. At first they experimented with the process of Lauth and Grimaux, which consists in the oxidation of benzyl-chloride, with an aqueous solution of lead nitrate; but the product made by this process was too dear. But they found that the decomposition of benzylidene-dichloride, by means of water, as observed by Cahours (Ann. Chem. Suppl. 2305) and Limprecht (Ann. Chen. I39, 316) gave them a means of producing this compound successfully, the reaction being as follows :- -

$$
\mathrm{C}_{6} \mathrm{H}_{5} \mathrm{CHCl}_{2}+\mathrm{OH}_{2}=\mathrm{C}_{6} \mathrm{H}_{5} \cdot \mathrm{CHO}+2 \mathrm{HCl} \text {. }
$$

This process, which they have successfully employed since March, 1878 , consists in the preparation of benzylidenedichloride from pure toluene, and in the subsequent treatment of this chlorinated body with milk of lime, at $100^{\circ} \mathrm{C}$.

I have stated that the group of colouring matters under consideration are called triphenylmethane derivatives, and to show how this has been proved to be the case, I must now refer very briefly to some of the theoretical work which has led to this knowledge. The most important of this refers to rosaniline. I have already drawn attention to the work of Hofmann, which gave us the first knowledge of the composition of this colouring matter, and the further information that it contained hydrogen, which could be displaced by phenyl and alcohol radicals; but as to the matter of constitution, I think the experiments of Caro and Wanklyn were the first, as they showed the relation which existed between rosaniline and aurine, or rosolic acid, and, in fact, produced rosolic acid from rosaniline; but it is to the beautiful researches of Emil and Otto Fischer that we arc in debted for a clear knowledge of the constitution of this class of colouring matter.
But to clear the ground before proceeding further, I must remind you that ordinary commercial rosaniline, or magenta, prepared from aniline and toluidines, is a mixture of colouring matters. This was first known by Mr. Nicholson, who found that for the production of the finest blues it was necessary to purify the base and separate one of the e before phenylating; but it is only of later years that the difference between these bodies has been carefully studied and explained. The base examined by Hofmann contained $\mathrm{C}_{20}$, and is the chief constituent of commercial rosaniline. The other contains $\mathrm{C}_{19}$, and is now called pararosaniline, because it is produced from aniline and paratoluidine. Similarly, in commercial aurine, two compounds are found, one containing $\mathrm{C}_{n_{0}}$, now called rosolic acid, and one containing $\mathrm{C}_{19}$, now called aurine; and these latter can be produced from the corresponding rosanilines; and Dale and Schorle nmer have also shown that aurine can be also converted into pararosaniline, by the action of ammonia ( $\mathscr{F}$. Chem. Soc., xxxii, $12 \mathrm{I}$ ).

Emil and Otto Fischer, however, by submitting the leaco compound of commercial rosaniline to the diazo reaction, obtained the hydrocarbon $\mathrm{C}_{20} \mathrm{H}_{18}$, and from rosaniline prepared from paratoluidine and aniline, the hydrocarbon $\mathrm{C}_{19} \mathrm{H}_{16}$.

And this latter hydrocarbon was found to be identical with Kekule's triphenylınethane-

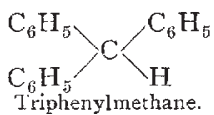

On nitrating this hydrocarbon they obtained a trinitro derivative, which, when reduced, gave the tri-amido body,

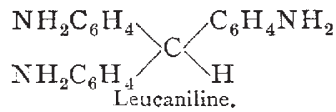

which is paraleucaniline, and by carefully heating its hydrochloride to $150-160^{\circ}$, it was converted into pararosaniline.

Also they found that by oxidising trinitrotriphenylmethane they obtained trinitrotriphenylcarbinol, and this when reduced gave pararosaniline direct.

From these results the constitution of the base is evidently -

$$
\begin{aligned}
& \mathrm{NH}_{2} \mathrm{C}_{6} \mathrm{H}_{4} \\
& \mathrm{NH}_{2} \mathrm{C}_{6} \mathrm{H}_{\text {Pararosaniline. }}
\end{aligned}>_{\mathrm{OH}}^{\mathrm{C}_{6} \mathrm{H}_{4} \mathrm{NH}_{2}}
$$

The salts- the hydrochloride, for example-being

$$
\begin{aligned}
& \mathrm{NH}_{2} \mathrm{C}_{6} \mathrm{H}_{4} \\
& \underset{2}{\mathrm{NH}_{2} \mathrm{C}_{6} \mathrm{H}_{4}}>\mathrm{C} / \mathrm{C}_{6} \mathrm{H}_{4} \mathrm{NH} . \mathrm{HCl} \\
& \text { Pararusanilinehydrochloride. }
\end{aligned}
$$

Similar results were obtained from the hydrocarbon from rosaniline; it is tolyldiphenylmethane :-

$$
\mathrm{C}_{6} \mathrm{H}_{4}\left(\mathrm{CH}_{3}\right)>\mathrm{C}<\mathrm{C}_{6} \mathrm{H}_{6} \mathrm{H}_{5}
$$

The rosolic acid and aurine corresponding to the rosanilines are constituted in an analogous manner :-

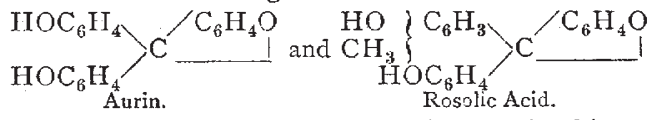

From these results we see the beautiful relationships of the various colouring matters of this series to each other, and by it obtain information which is of practical value, as well as theoretical. From the following formulæ of a few of these products their relationships are seen :-

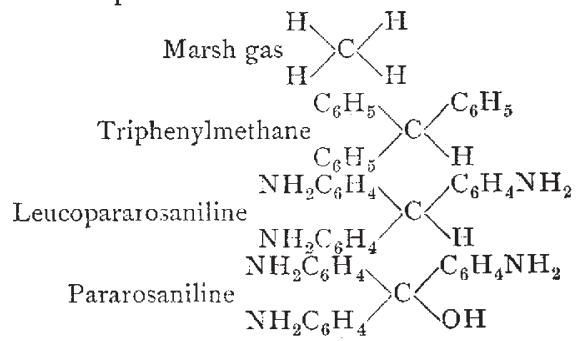




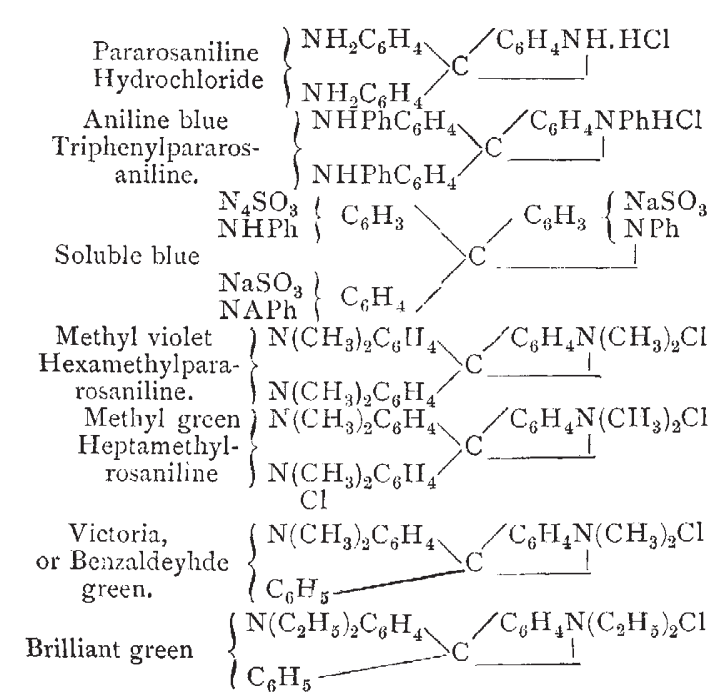

The effect of replacing hydrogen by hydrocarbon radicals in rosaniline is seen to result in the shade of colour becoming blue for each hydrogen replaced - the effects of those of high molecular weight, stich as phenyl, being to produce the bluest shades; thus triphenylrosaniline is blue, whilst hexamethylrosaniline is blueviolet, notwithstanding it contains six hydrogens replaced.

After all the replacements possible have been effected, as in hexamethylrosaniline, the result of the combination of the products with halogen compounds of methyl is very interesting. The particular group to which this is attached becomes of the nature of an ammonium, and the colour changes to green--i.e., methyl green-and this, like other ammonium compounds, when heated, dissociates, with loss of the halogen compound of methyl, and then hexamcthylrosaniline is reproduced. Again, if this ammonium group be replaced by phenyl, we a!so get a green-i.e., Victoria grcen.

The structure of some of these bodies has been proved by anolher most beautiful synthetical process, which has lately come into use-a process which enables us now not only to say that we employ tire volatile products of the distillation of coal, but also the coke itself; as carbonic oxide, in combination with chlorine, is one of the important agents-i.e., phosgene or carbonoxychloride is used. This product was discovered in 1812 by J. Davey.

In $1876 \mathrm{~W}$. Micl ler gave an account of his researches on the synthesis of aromatic ketones by means of phosgene (Ber. ix. 716), in which he showed by the action of this substance on dimethylaniline that a tetramethylised diamidobenzophenone was contained. This substance has, therefore, the constitution-

$$
\mathrm{N}\left(\mathrm{CH}_{3}\right)_{2} \mathrm{C}_{6} \mathrm{I}_{4}-\mathrm{CO}-\mathrm{C}_{6} \mathrm{IT}_{4}\left(\mathrm{Cl}_{3}\right)_{2} \mathrm{~N} \text {. }
$$

The formation of this product takes place in two phases, but I need not enter into that now.

The first experiments to turn Michler's synthetically prepared tetramethylated diamidobenzophene to practical account were made by Dr. A. Kern, in the works of Bindschedler, at Basle. Dr. Kern proved that an agent like pliosgene might be prodiced on a larger scale, and he invented a process to convert Michler's ketone base into methyl purple. This process was derived from the ketone synthesis of triphenylmethane from benzhydrol and benzene, and consisted in preparing the tetramethyldiamidobenzhydrol, and condensing the latter with dimethylaniline; thus the leuco base of hexamethylrosaniline was obtained, and then oxiclised with lead peroxidc. This process, which was too costly for practical purposes, has been superseded by one discovered by Dr. Caro, who has found that this ketone base can be made to form condensation products with dimethylaniline and other products directly, by the use of phosphorus trichloridethis substance converting it first into a chloride, which then reacts on the dimethylaniline, thus-

$$
\begin{aligned}
\mathrm{N}\left(\mathrm{CH}_{3}\right)_{2} \mathrm{C}_{6} \mathrm{H}_{4}-\mathrm{CCl}_{2}-\mathrm{C}_{6} \mathrm{H}_{4}\left(\mathrm{CHI}_{3}\right)_{2} \mathrm{~N}+\mathrm{N}(\mathrm{CH})_{2} \mathrm{C}_{6} \mathrm{II}_{5}= \\
\mathrm{N}\left(\mathrm{CH}_{3}\right)_{2} \mathrm{C}_{6} \mathrm{H}_{4}>\mathrm{C}_{6} \mathrm{H}_{4}\left(\mathrm{CH}_{3}\right)_{2} \mathrm{~N}, \mathrm{Cl}+\mathrm{HCl} \\
\quad \mathrm{N}\left(\mathrm{CH}_{3}\right)_{2} \mathrm{C}_{6} \mathrm{H}_{4}>\mathrm{C}+\cdots
\end{aligned}
$$

And this reaction takes place quantitatively, the body being so pure that it readily crystallises from water in prisms, like potas. sium permanganate, only with very much more brilliant lustre. These contain water of crystallisation. The condensation can also be effected with phosgene gas. The colouring matter obtained by this means is bluer than that obtained from dimethylaniline by oxidation, which consists chiefly of the pentamethyl compound. ${ }^{1}$

Diethylene can also be made into a ketone with phosgene or carbon oxychloride, and this product condensed with diethylaniline yields hexaethylpararosaniline.

Instead of dimethylaniline, dimethyl- $\alpha$-naphthylamine can be used, and in this case a beautiful blue colouring matter is obtained, and if a-phenylnaphthylamine, the Victoria blue is produced, and by varying the reaction in this kind of way a great variety of colouring matter can be synthetically prepared.

With ammonias this ketone condenses to form the new yellow colouring matter, auramine, with aniline phenylauramine. With quinoline it produces a green very similar to Victoria or benzaldehyde green. I must not, however, spend any more time over this interesting part of the subject, but may say here again we have pure scientific research, conducted for its own sake, bearing fruit. The discovery of W. Michler, which remained for seven years a matter of theoretical interest, now comes forward as a matter of practical value.

(To be continued.)

\section{THE DEVONIAN SYSTEM OF RUSSIA}

$\mathrm{M}$ P. VENUKOFF has recently given a general sketch of the Devonian rocks of Russia. As is well known, these rocks, so largely developed in Russia, contain such a peculiar fauna that geologists have been puzzled to establish a parallel betwcen them and the different subdivisions of the Devonian system of Western Europe. Two great areas of Devonian strata are known in Russia: that of the north-west and that of the central basin. From Esthonia and Livonia the former ex tends north-eastwards to Lake Onega and perhaps even to the White Sea, and southwards through Pskor and Vitebsk to Moghiber. In Smolensk only traces of Devonian rocks have been found ; but further south-east a great tract of these rocks runs through Tula, Orel, Voronesh, Ryazan, and Tamboff.

Prof. Grewinck, in his "Geologie von Livonia und Kurland" in $\mathbf{1 8 6 1}$, and again in 1879 , and Prof. Barbot de Marny, in the Russian Mining Fournal of 1878 , attempted to classify the Russian Devonian deposits; not to mention the earlier English work of Murchison, followed by those of Pander, Pacht, IIelmersen, and Kutorga, and recently by those of MM. Stuckenberg, Inostrantseff, and Romanovsky. The mixed characters of the fauna have thus always presented great difficulties in the way of satisfactory correlation.

The recent monograph by M. Tschernyskev ( $M e m$. Geol. Committee, $i$, 3) shows how rich a field remains to be explored before our knowledge of the Devonian fauna of Russia in any measure approaches complction.

M. Venukoff, in his részumé of the present condition of the problem, gives a brief account of all that is known as to the Russian Devonian system in each separate government, followed with an analysis of the work done by previous geologists. $\mathrm{He}$ then presents a detailed exposition of his own observations and conclusions in North.West and Central Russia; giving long lists of fossils which comprise the rich collections recently made by M. Antonowitsch. In the north-western basin three stratigraphical series have long been known: the lower sandstones, the middle limestones and dolomites, and the upper sandstones. 'The lower member contains only fishes and small Linsule, though on the Oyat the ichthyolites are accompanied with Rhynchonella livonita, Streplorhynchus crenistria, Avicula rostrata, Isocardia, and numerous Alga. The fauna of the limestones is mostly that of decper water, but even among these strata there occur occasionally-as at Lake Ilmen-beds of sandstone with shallow-water forms (the fishes Cociosteus, Asterolepis, Osteolepis, and the little Lingula bicarinata, Kut.) On the whole the midlde limestones of Pskov and Novgorod may be sub-divided into four stages or -zones characterised, the first, by Rhynchonella Meyendorfii, Rh. livonica, Spirifera muralis, Atrypa reticutaris, Orthis striatulat, and Strophalosia product-

See Patents, Caro, 4428, September, $x 883$; 4850, March r3, 1884 ; and 5038 , March 18, , 884 